\title{
HUBUNGAN ANTARA GAYA KEPEMIMPINAN, SEMANGAT KERJA DAN PENGEMBANGAN KARIR DENGAN KINERJA KARYAWAN DI PT. AGUNG AUTOMALL CABANG BENGKULU
}

\author{
Andriyani Prawitasari ${ }^{1)} \bullet$ Doki Bustari ${ }^{2)}$ \\ Universitas Dehasen Bengkulu \\ andriyaniprawitasari@gmai.com \\ dokibustari26@gmail.com
}

\begin{abstract}
The purpose of this study is to find out a correlation between leadership style, spirit and career development with employee performanceat PT. Agung Automall Bengkulu Branch with the samples of 91 employees. Due to all the population in this study were sampled, the sampling method was by census. Data were collected using questionnaires and analyzed using Spearman rank correlation and hypothesis testing $t$ test. Spearman rank test results there is a strong correlation between leadership style with employee performance at PT. Agung Automall Bengkulu Branch. This is reinforced by the results of hypothesis testing known to a significant, meaning that the leadership style has a positive and significant correlation with the performance of employees at PT. Agung Automall Bengkulu Branch. The results of the study for the correlation between spirit with employee performance at PT. Agung Automall Bengkulu Branch obtained a Spearman rank correlation with strong evaluation criteria. The results of the Spearman rank are also strengthened by the results of hypothesis testing with a significant, meaning that there is a significant correlation between organizational culture and performance.Career development has a moderate correlation with the performance of the employees of PT. Agung Automall Bengkulu Branch with Spearman rank correlation. This result is strengthened by testing the hypothesis with a significant, meaning that career development has a significant correlation with employee performance at PT. Agung Automall Bengkulu Branch.
\end{abstract}

\section{Keywords: Leadership Style, Work Spirit, Career Development, Performance}

\section{PENDAHULUAN}

Karyawan merupakan aset utama suatu perusahaan yang menjadi perencana dan pelaku aktif dari setiap aktivitas organisas yang tidak kalah pentingnya adalah perekrutan tenaga kerja tersebut harus sesuai dengan kebutuhan. Setiap karyawan yang direkrut harus mengerti kemampuan yang sesuai dengan jenis pekerjaan yang ditawarkan, hal ini dapat mengakibatkan tenaga kerja tersebut dapat bekerja secara maksimal sehingga akan meningkatkan produktivitas kerja oleh karena itu karyawan harus mempunyai semangat kerja yang tinggi untuk melaksanakan tugas dan pekerjaannya dengan baik. Menurut Sastrohadiwiryo. (2016:167) semangat kerja diartikan sebagai suatu kondisi rohaniah atau perilaku individu tenaga kerja untuk bekerja dengan giat dan konsekuen dalam mencapai tujuan yang ditetapkan perusahaan. Pada dasarnya pengertian dari semangat kerja dan kegairahan kerja ini tidak dapat dibedakan atau dengan kata lain sama. Semangat kerja dan kegairahan kerja ini merupakan salah satu faktor terpenting yang harus diperhatikan oleh pimpinan perusahaan, sebab menyangkut 
masalah kejiwaan para karyawan untuk mau berusaha lebih baik guna mencapai tujuan organisasi. Dengan meningkatnya semangat dan kegairahan kerja para karyawan tersebut diharapkan akan mencapai kinerja yang lebih baik di bidang pekerjaan mereka masing-masing sehingga akan tercapai tujuan perusahaan.

Selain dari gaya kepemimpinan dan semangat kerja, pengembangan karir juga akan mempengaruhi seseorang dalam bekerja. Karena dengan adanya pengembangan karir yang dijanjikan oleh perusahaan maka karyawan akan bekerja lebih giat karena karyawan yang memiliki prestasi yang baik akan mendapatkan jabatan yang meningkat. Pengembangan karir sangat dibutuhkan pada perusahaan karena dengan adanya penembangan karir maka seseorang akan lebih giat bekerja demi tercapainya target perusahaan. PT. Agung Automall cabang Bengkulu merupakan dealer resmi dari produk Toyota yang menjual berbagai macam jenis mobil merek Toyota. PT. Agung Automall Cabang Bengkulu memiliki suatu tujuan meningkatkan penjualan setinggi-tingginya pada setiap bulannya, untuk pencapaian target ini tentunyo tidak mudah karena harus dibimbing oleh seorang pemimpin yang mampu mengarahkan bawahannya agar para bawahan mampu mempengaruhi konsumen untuk melakukan pembelian mobil Toyota. Selain itu semangat kerja juga harus dimiliki oleh karyawan karena tanpa semangat kerja tujuan tidak akan tercapai. Berdasarkan latar belakang di atas maka peneliti tertarik untuk mengangkat judul "Hubungan Antara Gaya Kepemimpinan, Semangat Kerja dan Pengembangan Karir dengan Kinerja karyawan di PT. Agung Automall Cabang Bengkulu".

\section{LANDASAN TEORI}

\section{Gaya Kepemimpinan}

Gaya kepemimpinan merupakan proses mempengaruhi orang lain agar mau berperan serta dalam rangka memenuhi tujuan yang telah ditetapkan bersama, defenisi kepemimpinan akhirnya dikategorikan menjadi tiga elemen yaitu : Kepemimpinan merupakan proses, Kepemimpinan merupakan suatu konseprelasi (hubungan) antara pimpinan dan bawahan dan Kepemimpinan merupakan ajakan kepada orang lain. Susanto. (2014:115). Secara umum gaya kepemimpinan diartikan sebagai suatu kewanangan yang disertai kemampuan seseorang dalam memberikan pelayanan untuk menggerakan orang-orang yang berada dibawah koordinasinya dalam usaha mencapai tujuan yang ditetapkan suatu organisasi. Pelaksanaan kepemimpinan cenderung menumbuhkan kepercayaan, partisipasi, loyalitas, dan internal motivasi para bawahan dengan cara persuasif, hal ini semua akan diperoleh karena kecakapan, kemampuan, dan perilaku pimpinan tersebut. Menurut Hasibuan, Malayu.(2016:169) ada beberapa tipe, diantaranya: tipe karismatis, tipe paternalistis dan maternalistis, tipe militeristis, tipe otokratis, tipe laisser faire, tipe populistis, tipe administratif dan tipe demokratis.

Teori perilaku pemimpin merupakan teori yang menjelaskan bahwa perilaku khusus membedakan antara satu pemimpin dengan pemimpin lainnya. Pemimpin dalam kepemimpinannya secara khusus memiliki kemampuan lebih yang digunakan untuk keputusan yang diambil terhadap bawahannya dalam pencapaian tujuan. Menurut Rivai, Veithzal. 2014:11) menyatakan beberapa model kepemimpinan yaitu: model kepemimpinan kontingensi, model partisipasi pemimpin oleh Vroom dan Yetton, model jalur tujuan (path goal model), teori kepemimpinan situasional Hersey - Blanchar. Model kepemimpinan ini juga menyatakan bahwa gaya kepemimpinan yang paling efektif bervariasi dengan kesiapan karyawan yang mendefinisikan sebagai keinginan karyawan untuk berprestasi, kemauan untuk bertanggung 
jawab, kemauan yang berhubungan dengan tugas, keterampilan, dan pengalaman. Sasaran dan pengetahuan dari pengikut merupakan variabel penting dalam menentukan gaya kepemimpinan yang efektif. Indikator kepemimpinan menurut Hasibuan, Malayu.(2016:186) sebagai berikut :

a) Pemimpin berkewajiban menjabarkan program kerja yang menjadi keputusan yang kongkrit untuk dilaksanakan sesuai dengan prioritasnya masing-masing keputusan-keputusan itu harus jelas hubungannya dengan tujuan kelompok/organisasi.

b) Pemimpin harus mampu menterjemahkan keputusan-keputusan menjadi intruksi yang jelas, sesuai dengan kemampuan anggota yang melaksanakannya.

c) Pemimpin harus berusaha untuk mengembangkan dan menyalurkan kebebasan berpikir dan mengeluarkan pendapat baik secara perorangan maupun kelompok kecil. Pemimpin harus mampu menghargai gagasan, pendapat, saran,kritikanggotanya sebagai wujud dari partisipasinya. Usaha mengembangkan partisipasi anggota tidak sekedar ikut aktif dalam melaksanakan perintah, tetapi juga dalam memberikan informasi dan masukan untuk dijadikan bahan pertimbangan bagi pemimpin dalam membuat dan memperbaiki keputusan-keputusan.

d) Mengembangkan kerjasama yang harmonis,sehingga setiap anggota mengerjakan apa yang harus dikerjakannya, dan bekerjasama dalam mengerjakan sesuatu yang memerlukan kebersamaan. Pemimpin harus mampu memberikan pengakuan dan penghargaan terhadap kemampuan, prestasi atau kelebihan yang dimiliki setiap anggota kelompok/organisasinya.

e) Pemimpin harus membantu dalam mengembangkan kemampuan memecahkan masalah dan mengambil keputusan sesuai dengan batas tanggung jawab masing-masing. Setiap anggota harus didorong agar tumbuh menjadi orang yang mampu menyelesaikan masalahnya, dengan menghindari ketergantungan yang berlebihan dari pemimpian/orang lain. Setiap anggota harus dibina agar tidak menjadi orang yang selalu menunggu perintah.

\section{Semangat Kerja}

Menurut Nitisemito Alex S. (2015:160), semangat kerja adalah melakukan pekerjaan lebih giat sehingga dapat diharapkan lebih cepat dan lebih baik. Pendapat lain mengatakan bahwa semangat kerja merupakan perasaan yang memungkinkan seseorang bekerja untuk menghasilkan yang lebih banyak dan lebih baik. Ada beberapa penyebab rendahnya semangat kerja karyawa yang terkait dengan kurang diperhatikannya pengaturan kerja mengenai disiplin kerja, kondisi kerja dan kekurangan tenaga kerja yang terampil dan ahli dibidangnya yaitu : Pekerjaan yang terpecah-pecah, Kerja yang berulang-ulang, terlalu sedikit menggunakan keterampilan, daur kerja pendek, kerja remeh serta tidak adanya dukungan sosial.

Menurut Nitisemito Alex S (2015:186), faktor-faktor untuk mengukur semangat kerja adalah Absensi karena absensi menunjukkan ketidakhadiran karyawan dalam tugasnya, kerja sama dalam bentuk tindakan kolektif seseorang terhadap orang lain dan kepuasan kerja sebagai keadaan emosional yang menyenangkan atau tidak menyenangkan di mana para karyawan memandang pekerjaan mereka. Kedisiplinan sebagai suatu sikap dan tingkah laku yang sesuai peraturan organasasi dalam bentuk tertulis maupun tidak. Prakteknya bila suatu organisasi telah mengupayakan sebagian besar dari peraturan-peraturan yang ditaati oleh sebagian besar karyawan, maka kedisiplinan telah dapat ditegakkan 


\section{Pengembangan Karir}

Program pengembangan tidak dilakukan secara tiba-tiba atau asal menugaskan karyawan untuk mengikuti suatu program pengembangan, tetapi memiliki dasar atau alasan-alasan tertentu yang sebagian berbeda dengan alasan mengapa suatu pelatihan perlu dilakukan. Pengembangan lebih diarahkan kepada peningkatan kemampuan manajerial (soft competency), yaitu jenis kemampuan untuk mengelola karyawan dan membangun interaksi dengan orang lain, misalnya kemampuan memecahkan masalah atau berkomunikasi sebagai pemimpin. Ada beberapa alasan atau faktor penyebab perlunya dilakukan program pengembangan adalah Program pensiun karyawan, karyawan meninggal dunia, karyawan diberhentikan dari pekerjaan, karyawan keluar dari organisasi, rencana pengembangan bisnis dan organisasi, mempertahankan karyawan, memantapkan budaya perusahaan dan kepuasaan kerja.

\section{Kinerja}

Suatu organisasi, baik itu pemerintah maupun swasta, selalu digerakan oleh sekelompok orang yang berperan aktif untuk mencapai tujuan yang ingin dicapai dari organisasi tersebut. Tujuan organisasi tentunya tidak akan tercapai jika kinerja anggota atau karyawannya tidak maksimal. Kinerja karyawan dan kinerja organisasi memiliki keterkaitan yang sangat erat, tercapainya tujuan organisasi tidak bisa dilepaskan dari sumber daya yang dimiliki oleh organisasi yang digerakan atau dijalankan karyawan yang berperan aktif sebagai pelaku dalam upaya mencapai tujuan organisasi.

\section{METODOLOGI}

Penelitian ini termasuk jenis penelitian kualitatif, menurut Sugiyono. (2017: 9) penelitian kualitatif adalah penelitian yang berlandaskan pada filsafat postpostivisme digunakan untuk meneliti pada kondisi proyek yang alamiah. Desain penelitian yang akan digunakan adalah riset kausal, karena akan membuktikan hubungan sebab akibat atau hubungan mempengaruhi dan dipengaruhi dari variabel-variabel yang diteliti yaitu hubungan antara gaya kepemimpinan, semangat kerja dan pengembangan karir dengan kinerja karyawan Pada PT. Agung Automall Cabang Bengkulu. Populasi dalam penelitian ini adalah seluruh karyawan yang bekerja pada pada PT. Agung Automall Cabang Bengkulu sebanyak 91 orang karyawan.Adapun rincian sampel yang akan diteliti sebagai berikut:

\begin{tabular}{|l|l|l|}
\multicolumn{3}{|c}{ Tabel Sampel } \\
\hline No & Bagian & Jumlah Karyawan \\
\hline 1 & Bagian Penjualan & 18 \\
\hline 2 & Bagian Pemasaran & 31 \\
\hline 3 & Bagian Keuangan & 4 \\
\hline 4 & Bagian Akuntansi & 3 \\
\hline 5 & Bagian Personalia & 6 \\
\hline 6 & Bagian Gudang & 8 \\
\hline 7 & Bagian Bengkel & 21 \\
\hline & Total & 91 \\
\hline
\end{tabular}

Sumber : PT. Agung Automall Cabang Bengkulu, 2019 
Sampel adalah bagian dari jumlah dan karakteristik yang dimiliki oleh populasi tersebut (Sugiyono, 2017:62). Sampel dari penelitian ini adalah 91 orang karyawan pada PT. Agung Automall Cabang Bengkulu, karena semua populasi dalam penelitian ini dijadikan sampel, maka metode pengambilan sampel yang digunakan adalah total sampling/sensus. Data yang diperoleh dalam penelitian ini didapatkan langsung dari pengisian kuesioner (angket) yang ditujukan kepada responden.

Pertanyaan-pertanyaan pada angket tertutup dibuat dengan skala likert dengan skor 1-5 digunakan peneliti karena lebih sederhana dan memiliki nilai tengah yang digunakan untuk menjelaskan keragu-raguan atau netral dalam memilih jawaban. Metode analisis yang digunakan dalam penelitian ini adalah menggunakan Korelasi Rank Spearman dan uji hepotesis.

\section{HASIL DAN PEMBAHASAN}

\section{Uji Validitas}

Pengujian validitas digunakan untuk mengetahui layak atau tidaknya indikator digunakan dalam penelitian. Hasil pengujian validitas dari indikator penelitian seperti pada tabel berikut :

Tabel Uji Validitas Indikator Penelitian

\begin{tabular}{|c|l|c|c|c|}
\hline No & \multicolumn{1}{|c|}{ Item Pernyataan } & R-tabel & R-hitung & Keterangan \\
\hline \multicolumn{2}{|c|}{ Gaya Kepemimpinan (X1) } & & & \\
\hline 1 & X1.1 & 0,203 & 0,685 & Valid \\
\hline 2 & X1.2 & 0,203 & 0,769 & Valid \\
\hline 3 & X1.3 & 0,203 & 0,647 & Valid \\
\hline 4 & X1.4 & 0,203 & 0,554 & Valid \\
\hline 5 & X1.4 & 0,203 & 0,640 & Valid \\
\hline 6 & X1.6 & 0,203 & 0.612 & Valid \\
\hline 7 & X1.7 & 0,203 & 0,544 & Valid \\
\hline 8 & X1.8 & 0,203 & 0,637 & Valid \\
\hline 9 & X1.9 & 0,203 & 0,681 & Valid \\
\hline 10 & X1.10 & 0,203 & 0,585 & Valid \\
\hline 11 & X1.11 & 0,203 & 0,564 & Valid \\
\hline 12 & X1.12 & 0,203 & 0,578 & Valid \\
\hline Semangat Kerja (X2) & & & \\
\hline 1 & X2.1 & 0,203 & 0,682 & Valid \\
\hline 2 & X2.2 & 0,203 & 0,500 & Valid \\
\hline 3 & X2.3 & 0,203 & 0,720 & Valid \\
\hline 4 & X2.4 & 0,203 & 0,619 & Valid \\
\hline 5 & X2.4 & 0,203 & 0,648 & Valid \\
\hline 6 & X2.6 & 0,203 & 0,634 & Valid \\
7 & X2.7 & 0,203 & 0,661 & Valid \\
8 & X2.8 & 0,203 & 0,702 & Valid \\
9 & X2.9 & 0,203 & 0,529 & Valid \\
10 & X2.10 & 0,203 & 0,299 & Valid \\
11 & X2.11 & 0,203 & 0,370 & Valid \\
12 & X2.12 & & & Valid \\
\hline
\end{tabular}




\begin{tabular}{|c|c|}
\hline \multicolumn{2}{|c|}{ Pengemban } \\
\hline 1 & X3.1 \\
\hline 2 & X3.2 \\
\hline 3 & X3.3 \\
\hline 4 & X3.4 \\
\hline 5 & X3.4 \\
\hline 6 & X3.6 \\
\hline 7 & X3.7 \\
\hline 8 & X3.8 \\
\hline 9 & X3.9 \\
\hline 10 & X3.10 \\
\hline 11 & X3.11 \\
\hline 12 & X3.12 \\
\hline
\end{tabular}

Kinerja (Y)

\begin{tabular}{c|c}
1 & Y.1 \\
2 & Y.2 \\
3 & Y.3 \\
4 & Y.4 \\
5 & Y.5 \\
6 & Y.6 \\
7 & Y.7 \\
8 & Y.8 \\
9 & Y.9 \\
10 & Y.10 \\
11 & Y.11 \\
12 & Y.12 \\
13 & Y.13 \\
14 & Y.14 \\
15 & Y.15 \\
16 & Y.16 \\
17 & Y.17 \\
18 & Y.18 \\
19 & Y.19 \\
20 & Y.20 \\
21 & Y.21
\end{tabular}

\begin{tabular}{|l|l|l}
0,203 & 0,371 & Valid \\
0,203 & 0,459 & Valid \\
0,203 & 0,385 & Valid \\
0,203 & 0,399 & Valid \\
0,203 & 0,411 & Valid \\
0,203 & 0,559 & Valid \\
0,203 & 0,406 & Valid \\
0,203 & 0,356 & Valid \\
0,203 & 0,467 & Valid \\
0,203 & 0,313 & Valid \\
0,203 & 0,293 & Valid \\
0,203 & 0,410 & Valid
\end{tabular}

\begin{tabular}{|l|l|l|}
0,203 & 0,459 & Valid \\
0,203 & 0,440 & Valid \\
0,203 & 0,226 & Valid \\
0,203 & 0,530 & Valid \\
0,203 & 0,463 & Valid \\
0,203 & 0,464 & Valid \\
0,203 & 0,237 & Valid \\
0,203 & 0,370 & Valid \\
0,203 & 0,453 & Valid \\
0,203 & 0,502 & Valid \\
0,203 & 0,477 & Valid \\
0,203 & 0,444 & Valid \\
0,203 & 0,512 & Valid \\
0,203 & 0,390 & Valid \\
0,203 & 0,364 & Valid \\
0,203 & 0,656 & Valid \\
0,203 & 0,568 & Valid \\
0,203 & 0,492 & Valid \\
0,203 & 0,445 & Valid \\
0,203 & 0,510 & Valid \\
0,203 & 0,434 & Valid
\end{tabular}

Berdasarkan tabel diatas terlihat bahwa seluruh indikator penelitian yang memiliki tingkat validitas yang sesuai dengan kriteria yang diajukan pada penelitian ini, yaitu semua indikator memiliki nilai R-hitung > R-tabel, maka semua indikator yang digunakan dalam penelitian ini valid dan dapat digunakan sebagai alat penelitian.

\section{Uji Reliabilitas}

Hasil uji reliabelitas yang dilakukan dengan menggunakan program statistik SPSS maka diperoleh hasil cronbach's alpha lebih besar dari 0,60 untuk ketiga variabel. 
Tabel Uji Reliabilitas Indikator Penelitian

\begin{tabular}{|l|c|l|}
\hline \multicolumn{1}{|c|}{ Variabel } & $\begin{array}{c}\text { Cronbach } \\
\text { Alpha }\end{array}$ & \multicolumn{1}{c|}{ Keterangan } \\
\hline Gaya Kepemimpinan (X1) & 0,754 & $\begin{array}{l}\text { Reliabel } \\
\text { Cronbach Alpha }>\text { Taraf Signifikan }(0,6)\end{array}$ \\
\hline Semangat Kerja (X2) & 0,725 & $\begin{array}{l}\text { Reliabel } \\
\text { Cronbach Alpha }>\text { Taraf Signifikan }(0,6)\end{array}$ \\
\hline Pengembangan Karir (X3) & 0,672 & $\begin{array}{l}\text { Reliabel } \\
\text { Cronbach Alpha }>\text { Taraf Signifikan }(0,6)\end{array}$ \\
\hline Kinerja (Y) & 0,710 & Cronbach Alpha $>$ Taraf Signifikan $(0,6)$ \\
\hline
\end{tabular}

Berdasarkan tabel diatas dapat diketahui bahwa nilai Cronbach Alpha lebih besar dari pada taraf signifikan60\%(0,6), sehingga dapat disimpulkan bahwa instrumen dalam penelitian ini reliabel.

\section{Analisa Korelasi Rank Spearman}

1. Hubungan Gaya kepemimpinan dengan Kinerja Karyawan Pada PT. Agung Automall Cabang Bengkulu.

Tabel Hasil Korelasi Rank Spearman Hubungan Gaya Kepemimpinan Dengan Kinerja Correlations

\begin{tabular}{|lll|r|r|}
\hline & & & Gaya Kepemimpinan & \multicolumn{1}{c|}{ Kinerja } \\
\hline Spearman's rho & Gaya & Correlation & 1.000 & $.622^{* *}$ \\
& Kepemimpinan & Coefficient &. & .000 \\
& & Sig. (2-tailed) & 91 & 91 \\
\cline { 2 - 5 } & $\mathrm{N}$ & $.622^{* *}$ & 1.000 \\
& Kinerja & Correlation & .000 &. \\
& & Coefficient & 91 & 91 \\
& & Sig. (2-tailed) & & \\
& & $N$ & & \\
\end{tabular}

SPSS di atas diketahui bahwa besar korelasi promosi jabatan dengan kinerja karyawan pada PT. Agung Automall Cabang Bengkulu adalah sebesar 0,622, artinya gaya kepemimpinan dengan kinerja karyawan pada PT. Agung Automall Cabang Bengkulu memiliki korelasi yang kuat karena angka 0,622 terletak diantara angka 0,60-0,799. Hal ini menunjukkan bahwa terdapat korelasi yang kuat dan positif antara gaya kepemimpinan dengan kinerja karyawan pada PT. Agung Automall Cabang Bengkulu, ini menggambarkan jika gaya kepemimpinan meningkat maka kinerja karyawan juga akan meningkat. 
2. Hubungan Semangat kerja dengan Kinerja Karyawan pada PT. Agung Automall Cabang Bengkulu.

Tabel korelasi rank spearman untuk hubungan budaya organisaisi

\section{Correlations}

\begin{tabular}{|cll|r|r|}
\hline & & Semagat Kerja & Kinerja \\
\hline Spearman's rho Semagat & Correlation & 1.000 & $.744^{* *}$ \\
& Kerja & Coefficient &. & .000 \\
& Sig. (2-tailed) & 91 & 91 \\
\cline { 2 - 5 } & $N$ & $.744^{* *}$ & 1.000 \\
\cline { 2 - 5 } & Kinerja & Correlation & .000 &. \\
& Coefficient & 91 & 91 \\
& Sig. (2-tailed) & & \\
& $N$ & & \\
\end{tabular}

Output SPSS di atas maka diketahui bahwa besar korelasi semangat kerja dengan kinerja karyawan pada PT. Agung Automall Cabang Bengkulu adalah sebesar 0,744. Artinya semangat kerja dengan kinerja karyawan pada PT. Agung Automall Cabang Bengkulu memiliki korelasi yang kuat karena angka 0,744 terletak diantara angka 0,60-0,799.

3. Hubungan Pengembangan Karir dengan Kinerja Karyawan Pada PT. Agung Automall Cabang Bengkulu

Tabel Korelasi Rank Spearman Hubungan Pengembangan Karir Dengan Kinerja

\section{Correlations}

\begin{tabular}{|ll|r|r|}
\hline & \multicolumn{1}{|c|}{$\begin{array}{c}\text { Peng } \\
\text { Karir }\end{array}$} & \multicolumn{1}{c|}{ Kinerja } \\
\hline Spearman's rho Peng Karir Correlation & 1.000 & \multicolumn{1}{c|}{$.589^{* * *}$} \\
& Coefficient & & .000 \\
& Sig. (2-tailed) & 91 & 91 \\
& Correlation & $.589^{* *}$ & 1.000 \\
\cline { 2 - 4 } & Kinerja & .000 &. \\
& Sig. (2-tailed) & 91 & 91 \\
& $N$ & \\
\hline
\end{tabular}

Artinya pengembangan karir dengan kinerja karyawan pada PT. Agung Automall Cabang Bengkulu memiliki korelasi yang sedang karena angka 0,589 terletak diantara angka 0,40 0,599 .

\section{Pengujian Hipotesis}

Guna menguji tingkat signifikansi korelasi rank spearman antara gaya kepemimpinandengan keputusan kerja karyawan pada PT. Agung Automall Cabang Bengkulu maka dilakukan uji hipotesis statistik dengan menggunakan bantuan SPSS for windows 21 
1. Hubungan Gaya kepemimpinan dengan Kinerja Karyawan Pada PT. Agung Automall Cabang Bengkulu

Tabel Hasil Uji Hipotesis Hubungan Gaya Kepemimpinan Dengan Kinerja

\begin{tabular}{|c|c|c|c|c|}
\hline & & & $\begin{array}{c}\text { Gy } \\
\text { Kepemimpinan }\end{array}$ & Kinerja \\
\hline \multirow[t]{2}{*}{$\begin{array}{l}\text { Spearman's } \\
\text { rho }\end{array}$} & $\begin{array}{l}\text { Gy } \\
\text { Kepemimpinan }\end{array}$ & $\begin{array}{l}\text { Correlation } \\
\text { Coefficient } \\
\text { Sig. (2-tailed) } \\
N\end{array}$ & $\begin{array}{r}1.000 \\
. \\
91 \\
\end{array}$ & $\begin{array}{r}.622^{* *} \\
.000 \\
91 \\
\end{array}$ \\
\hline & Kinerja & $\begin{array}{l}\text { Correlation } \\
\text { Coefficient } \\
\text { Sig. (2-tailed) } \\
N\end{array}$ & $\begin{array}{r}.622^{* * *} \\
.000 \\
91\end{array}$ & $\begin{array}{r}1.000 \\
. \\
91\end{array}$ \\
\hline
\end{tabular}

Berdasarkan tabel di atas diketahui nilai signifikan sebesar 0,000, adapun hipotesis yang digunakan dalam pengujian ini adalah:

$\mathrm{H}_{01}$ : Gaya kepemimpinan tidak mempunyai hubungan yang signifikan dengan kinerja karyawan pada PT. Agung Automall Cabang Bengkulu

$\mathrm{H}_{\mathrm{a} 1}$ : $\quad$ Gaya kepemimpinan mempunyai hubungan yang signifikan dengan kinerja karyawan pada PT. Agung Automall Cabang Bengkulu

Nilai signifikan sebesar 0,000 lebih kecil dari 0,05 maka $\mathrm{H}_{\mathrm{a} 1}$ diterima dan $\mathrm{H}_{01}$ ditolak yang berarti gaya kepemimpinan mempunyai hubungan yang signifikan dengan kinerja karyawan pada PT. Agung Automall Cabang Bengkulu

2. Hubungan Semangat kerja dengan Kinerja PT. Agung Automall Cabang Bengkulu

Tabel Hasil Uji Hipotesis Hubungan Semangat kerja Dengan Kinerja

\section{Correlations}

\begin{tabular}{|c|c|c|c|c|}
\hline & & & Smgt Kerja & Kinerja \\
\hline \multirow[t]{2}{*}{$\begin{array}{l}\text { Spearman's } \\
\text { rho }\end{array}$} & Smgt Kerja & $\begin{array}{l}\text { Correlation } \\
\text { Coefficient } \\
\text { Sig. (2-tailed) } \\
N\end{array}$ & $\begin{array}{r}1.000 \\
. \\
91\end{array}$ & $\begin{array}{r}.744^{* *} \\
.000 \\
91\end{array}$ \\
\hline & Kinerja & $\begin{array}{l}\text { Correlation } \\
\text { Coefficient } \\
\text { Sig. (2-tailed) } \\
N\end{array}$ & $\begin{array}{r}.744^{* *} \\
.000 \\
91\end{array}$ & 1.000 \\
\hline
\end{tabular}

Tabel di atas diketahui nilai signifikan sebesar 0,000, adapun hipotesis yang digunakan dalam pengujian ini adalah: 
$\mathrm{H}_{02}$ : Semangat kerja tidak mempunyai hubungan yang signifikan dengan kepuasna kerja karyawan pada PT. Agung Automall Cabang Bengkulu

$\mathrm{H}_{\mathrm{a} 2}$ : $\quad$ Semangat kerja mempunyai hubungan yang signifikan dengan kinerja karyawan pada PT. Agung Automall Cabang Bengkulu

Nilai signifikan sebesar 0,000 lebih kecil dari 0,05 maka $\mathrm{H}_{a 1}$ diterima dan $\mathrm{H}_{01}$ ditolak yang berarti semangat kerja mempunyai hubungan yang signifikan dengan kinerja karyawan pada PT. Agung Automall Cabang Bengkulu.

3. Hubungan Pengembangan karir dengan Kinerja PT. Agung Automall Cabang Bengkulu

Tabel Hasil Uji Hipotesis Hubungan Pengembangan Karir Dengan Kinerja

\section{Correlations}

\begin{tabular}{|c|c|c|c|c|}
\hline \multirow{7}{*}{$\begin{array}{l}\text { Spearman's } \\
\text { rho }\end{array}$} & & & Peng Karir & Kinerja \\
\hline & \multirow[t]{3}{*}{ Peng Kari } & $\begin{array}{l}\text { Correlation } \\
\text { Coefficient }\end{array}$ & 1.000 & $.589^{* *}$ \\
\hline & & Sig. (2-tailed) & & .000 \\
\hline & & $N$ & 91 & 91 \\
\hline & \multirow[t]{3}{*}{ Kinerja } & $\begin{array}{l}\text { Correlation } \\
\text { Coefficient }\end{array}$ & $.589^{* *}$ & 1.000 \\
\hline & & Sig. (2-tailed) & .000 & \\
\hline & & $N$ & 91 & 91 \\
\hline
\end{tabular}

Berdasarkan tabel di atas diketahui nilai signifikan sebesar 0,000, adapun hipotesis yang digunakan dalam pengujian ini adalah:

$\mathrm{H}_{03}$ : Pengembangan karir tidak mempunyai hubungan yang signifikan dengan kepuasna kerja karyawan pada PT. Agung Automall Cabang Bengkulu

$\mathrm{H}_{\mathrm{a} 3}$ : Pengembangan karir mempunyai hubungan yang signifikan dengan kinerja karyawan pada PT. Agung Automall Cabang Bengkulu

Nilai signifikan sebesar 0,000 lebih kecil dari 0,05 maka $\mathrm{H}_{\mathrm{a} 1}$ diterima dan $\mathrm{H}_{01}$ ditolak yang berarti pengembangan karir mempunyai hubungan yang signifikan dengan kinerja karyawan pada PT. Agung Automall Cabang Bengkulu

Tabel Hasil Pengujian Korelasi Rank Spearman dengan Hipotesis

\begin{tabular}{clccc} 
No & \multicolumn{1}{c}{ Variabel } & $\mathbf{P}$ & Ket & Nilai Signifikan \\
1 & Gaya kepemimpinan & 0,622 & Kuat & 0,000 \\
2 & Semangat kerja & 0,744 & Sedang & 0,000 \\
3 & Pengembangan karir & 0,589 & Sangat & 0,000
\end{tabular}

\section{SIMPULAN}

Hasil analisis dan pembahasan tentang hubungan gaya kepemimpinan, semangat kerja dan pengembangan karir dengan kinerja karyawan PT. Agung Automall Cabang Bengkulu, maka penulis menyimpulkan sebagai berikut: 
1. Hasil pengujian rank spearman terdapat hubungan yang kuat antara gaya kepemimpinan dengan kinerjan karyawan pada PT. Agung Automall Cabang Bengkulu dengan nilai korelasi sebesar 0,622. Hal ini diperkuat dengan hasil pengujian hipotesis diketahui nilai signifikan sebesar $0,000<0,05$, artinya antara gaya kepemimpinan memiliki hubungan yang positif dan signifikan dengan kinerja karyawan pada PT. Agung Automall Cabang Bengkulu

2. Hasil penelitian untuk hubungan semangat kerja dengan kinerja karyawan pada PT. Agung Automall Cabang Bengkulu diperoleh nilai korelasi rank spearman sebesar 0,744 dengan kriteria penilaian kuat. Hasil rank spearman ini diperkuat juga dengan hasil uji hipotesis dengan nilai signfikan sebsar $0,000<0,05$, artinya terdapat hubungan yang signifikan antara budaya organisai dengan kinerja.

3. Pengembangan karir memiliki hubungan yang sedang dengan kinerja karyawan PT. Agung Automall Cabang Bengkulu dengan nilai korelasi rank spearman sebesar 0,589. Hasil ini diperkuat dengan pengujian hipotesis dengan nilai signifikan sebesar $0,000<0,05$, artinya pengembangan karir memiliki hubungan yang signifikan dengan kepuasan karyawan pada PT. Agung Automall Cabang Bengkulu.

Berdasarkan dengan kesimpulan yang telah dikemukakan, peneliti memberikan saran yaitu:

1. Disarankan kepada PT. Agung Automall Cabang Bengkulu untuk lebih memperhatikan karyawannya, karena perhatian dari pimpinan akan menimbulkan kinerja yang tinggi dari karyawan.

2. Disarankan kepada PT. Agung Automall Cabang Bengkulu untuk memperhatikan pengembangan karir dari karywnanya karena karyawan yang diberikan promosi jabatan karena karirnya bagus akan terus meningkatkan prestasinya dalam bekerja, begitu juga dengan karyawan yang lainnya akan termotivasi untuk bekerja lebih baik karena adanya pengembangan karir.

\section{DAFTAR PUSTAKA}

Ghozali, Imam. (2015). Aplikasi Analisis Multivariate dengan Program SPSS. (Edisi Ke 4). Semarang: Badan Penerbit Universitas Diponegoro

Harbani, Pasolong. 2017. Kepemimpinan Birokrasi. Bandung: CV.Alfabeta Hasibuan, Malayu. 2016. Manajemen Sumber Daya Manusia. Jakarta : PT Bumi Aksara. Hayati, (2015) Hubungan Kompensasi, Semangat kerja dan Motivasi Kerja Dengan Kinerja Karyawan SMA Negeri 5 Kaur. Skripsi Universitas Dehasen Bengkulu

Mahmudi. (2015). Manajemen Kinerja Sektor Publik. Yogyakarta: UPP AMP YKPN.

Mangkunegara. (2016). Manajemen Sumber Daya Manusia Perusahaan. Bandung: PT. Remaja Rosdakarya

Masyitah. (2015) Hubungan Kepemimpinan dan Kedisiplinan terhadap Kinerja Karyawan pada Kantor Pimpinan Nasal Kabupaten Kaur. Skripsi Universitas Dehasen Bengkulu

Moekijat. (2017). Manajemen Sumber Daya Manusia, cetakan kesembilan, Bandung: Mandar Maju

Nitisemito Alex S. (2015). Manajemen Personalia, Jakarta: Ghalia Indonesia

Prawirosentono, Suryadi. (2016). Kebijakan Kinerja Karyawan. Yogyakarta: BPFE.

Rivai, Veithzal. Deddy Mulyadi. (2017). Kepemimpinan dan Perilaku Organisasi Edisi Ketiga.

Jakarta : PT. Rajagrafindo Persada

Siagian, S.P. (2017). Teori dan Praktek Kepemimpinan. Jakarta: Rineka Cipta 
Steers Richard. M. (2007). Efektivitas Organisasi. (Terjemahan). Jakarta: Erlangga

Sugiyono. (2017). Metode Penelitian Kunatitatif Kualitatif dan R\&D. Cetakan Ke-18. Bandung: Alfabeta.

Sulistiyani Ambar Tegu. Rosidah. (2014). Manajemen Sumber Daya Manusia. Yogyakarta : Graha Ilmu

Suparyadi, (2016). Manajemen Sumber Daya Manusia, Menciptakan Keunggulan Bersaing Berbasis Kompetensi SDM. Edisi-1, First Published. Yogyakarta: Penerbit Andi.

Susanto, Azhar, (2014). Sistem Informasi Manajemen. Bandung: Linggar Jaya

Sutrisno, Edy. (2015). Budaya Organisasi. Cetakan kedua. Jakarta: KencanaPranada Media Group.

Tulaini, Ratemi. (2013). Analisis Gaya Kepemimpinan Dalam Upaya Meningkatkan Semangat Kerja Karyawan Pada PT. Nusantara Surya Sakti Manna Bengkulu Selatan. Skripsi Universitas Dehasen Bengkulu

Umar, Husein. (2014). Desain Penelitian MSDM dan Perilaku Karyawan, Seri Desain Penelitian Bisnis - No 1, PT Rajagrafindo Persada Jakarta

Zainun, Buchari. (2014). Manajemen dan Motivasi. Jakarta: Erlangga. 